This is the postprint version of the following article: Rodríguez-Fernández D, Langer J, HenriksenLacey M, Liz-Marzán LM. Hybrid Au-SiO2Core-Satellite Colloids as Switchable SERS Tags. Chemistry of Materials 2015;27(7):2540-2545, which has been published in final form at 10.1021/acs.chemmater.5b00128. This article may be used for non-commercial purposes in accordance with ACS Terms and Conditions for Self-Archiving. 


\title{
Hybrid $\mathrm{Au}-\mathrm{SiO}_{2}$ Core-Satellite Colloids as Switchable SERS Tags
}

\author{
Denis Rodríguez-Fernández, ${ }^{a}$ Judith Langer, ${ }^{\mathrm{a}}$ Malou Henriksen-Lacey ${ }^{\mathrm{a}}$ and Luis M. Liz- \\ Marzán ${ }^{\mathrm{a}, \mathrm{b} *}$
}

${ }^{a}$ Bionanoplasmonics Laboratory, CIC biomaGUNE, Paseo de Miramón 182, 20009 Donostia - San Sebastian, Spain;

${ }^{b}$ Ikerbasque, Basque Foundation for Science, 48013 Bilbao, Spain;

KEYWORDS. Gold, self-assembly, multiplex, SERS, cells.

\begin{abstract}
Au-silica self-assembled nanostructures are reported as multiplex surface enhanced Raman scattering (SERS) tags for bioimaging applications. These hybrid colloidal particles were obtained by hetero-assembly of $\mathrm{Au}-\mathrm{SiO}_{2} \mathrm{Janus}$ particles with smaller Au spheres and two Raman active molecules that can be independently imaged by varying the wavelength of the excitation laser. The Janus structure of $\mathrm{Au}-\mathrm{SiO}_{2}$ not only directs the assembly but also provides physical separation of the Raman tags and colloidal stability thereby facilitating complete silica encapsulation. The bioimaging capabilities of this system are demonstrated through SERS mapping of individual cells.
\end{abstract}

\section{INTRODUCTION}

Raman spectroscopy is based on the inelastic scattering of monochromatic photons under excitation of characteristic vibrational modes of a molecule, polymer or material, offering the unambiguous determination of their chemical identity, geometrical structure or oxidation state. Raman scattering is an intrinsically weak process due to the low probability of scattering events, leading to very small cross sections $(\approx 10$ $\left.{ }^{30} \mathrm{~m}^{2}\right)$. Notwithstanding, the local enhancement of the electromagnetic (EM) field close to plasmonic nanoparticles, when exposed to an external light source, can lead to the enhancement of Raman scattering cross sections by many orders of magnitude, which is known as surface enhanced Raman scattering (SERS). ${ }^{1-5}$ When plasmonic nanoparticles are in close proximity, the enhancement of the EM field is even higher due to coupling of individual localized surface plasmon resonances (LSPRs), generating so called hot spots ${ }^{6}$ and allowing even more sensitive detection, down to the single molecule detection limit. ${ }^{7-15}$

Analytical applications are often based on the detection of multiple SERS labels which can be distinguished by their individual spectral fingerprints. Common strategies aim at either the detection of molecules, parts of proteins or cells through direct scattering enhancement of the analyte or at an indirect detection of nanoparticle tags labeled with a Raman-active dye (also referred to as "color") acting as signal amplifier. $^{16-21}$ Dye-encoded SERS nanotags have also been proposed as a powerful tool for imaging cell cultures due to their high sensitivity even in complex media. ${ }^{22-25}$ This application requires effective SERS nanotags with improved stability and no toxicity, e.g. by adequate coating of the tag. Natan and coworkers reported the fabrication and SERS performance of dye-labeled tags coated with a protective glass shell, ${ }^{26}$ whereas Doering and Nie successfully synthesized silica coated dye-embedded nanoparticles. ${ }^{27}$ The SERS brightness of the nanotags could be enhanced through labeling of the nanoparticle with resonant Raman reporter molecules. ${ }^{28}$ Dual-wavelength surface enhanced resonance Raman scattering (SERRS) was applied to quantify five different
DNA sequences with low detection limit using dye-labeled nanoparticles which were resonant for 514.5 or $632.8 \mathrm{~nm}$ excitation wavelengths. ${ }^{29}$ Another strategy to increase the sensitivity of the nanotag comprises positioning the Raman label within a hot spot between two nanoparticles. Aggregation can be induced by the organic dye molecule itself forming multiparticle assemblies ${ }^{30}$ or alternatively, by addition of salt to the labeled particles prior silica coating. ${ }^{31}$ Controlled formation of nanoaggregates was also demonstrated using dithiols as linkers, ${ }^{32-34}$ and cancer cells were recently imaged using silica-coated nanoparticle dimers labeled with $4^{-}$ mercaptobenzoic acid (4-MBA). ${ }^{35}$

Special effort has been made to develop efficient SERS nanotags with non-invasive, in vivo multiplex imaging potential. ${ }^{25}$, 36-39 Zavaleta et al. demonstrated the in vivo detection of 10 different separately injected nanotags and the distinction of 5 synchronously injected nanotags to a nude mouse. ${ }^{37}$ Complex multi-color (=multi-functional) nanotags were recently designed for the combined application of analytical (imaging) methods where each color selectively acts as a label for a specific technique, e.g. fluorescence, SERS, photothermal imaging, MRI etc. ${ }^{40-43}$ We propose here a synthetic procedure to prepare hybrid core-satellite colloidal particles comprising differently sized Au spheres in close contact. We loaded these particle clusters with two different dye molecules and then covered them with silica to fix and protect the nanostructures for use as nanoantennas in SERS imaging applications using living cells.

Although examples of similar structures can be found in the literature, such as dimers and trimers of $\sim 100 \mathrm{~nm} \mathrm{Au}$ particles, ${ }^{44,45}$ or the more recently reported satellite particles prepared by a masking desilanization process, ${ }^{46}$ our strategy exploits the Janus behavior of $\mathrm{Au}-\mathrm{SiO}_{2}$ particles to restrict the area where the assembly can be produced and therefore to achieve a better control over the final geometry. ${ }^{47}$ This configuration additionally allows the controlled introduction of two different dyes at specific locations within the composite particles, 4-mercaptobenzoic acid (4-MBA) under the silica shell of the Janus particle and rhodamine $B$ isothiocyanate $(\mathrm{RhB})$ within the hot spots generated during 
the assembly. Significant differences in the energy dependence of the molecular Raman scattering cross section permit the interference-free detection of the individual components by selecting the adequate excitation wavelength. As a result, both labels can be independently traced for SERS imaging purposes by simply varying the laser excitation color. We propose that our method is advantageous because it allows multiplex SERS imaging using a relatively simple colloid chemistry approach. The hybrid satellites described here serve as a proof of concept to demonstrate the capabilities of this type of assembled nanostructures and open the way to the development of new architectures with even higher complexity for future applications in sensing, diagnosis or drug delivery.

\section{EXPERIMENTAL SECTION}

Synthesis of the building blocks. Au nanospheres of $15 \mathrm{~nm}$ average diameter were prepared by means of Turkevich's method. ${ }^{48}$ The as prepared particles were transferred into ethanol upon exchanging the capping agent to poly(vinylpyrrolidone) (PVP, $\mathrm{M}_{\mathrm{w}} 10,000 \mathrm{~g} / \mathrm{mol}$ ). The particles were incubated for $24 \mathrm{~h}$ with the polymer (6o molecules $/ \mathrm{nm}^{2}$ ) at room temperature, then centrifuged at 6000 rpm and redispersed in ethanol adjusting the final [Au] to $0.42 \mathrm{mM}^{49}$ The synthesis of $\mathrm{Au}-\mathrm{SiO}_{2}$ Janus nanoparticles was carried out as previously described..$^{5}$ First, $27 \mathrm{~mL}$ of Au@citrate spheres (40 nm av. diameter) were prepared, centrifuged at $2100 \mathrm{~g}$ for $20 \mathrm{~min}$, washed and dispersed in Milli-Q water (10 mL). The seeds ([Au] $\sim 0.3 \mathrm{mM}$ in the final mixture) were then added dropwise under vortex stirring to a mixture of 2-propanol $(38 \mathrm{~mL})$ and $\mathrm{H}_{2} \mathrm{O}(12 \mathrm{~mL})$, containing 4-MBA $(400 \mu \mathrm{L}, 5 \mathrm{mM}$ in EtOH) and polyacrylic acid (PAA, $400 \mu \mathrm{L}, \mathrm{M}_{\mathrm{w}} 250$,ooo g/mol, 6.45·10 ${ }^{-5} \mathrm{M}$ in $\mathrm{H}_{2} \mathrm{O}$ ). After stirring for $30 \mathrm{~min}$ to induce self-assembly of the ligands over the surface, ammonium hydroxide $(1.8 \mathrm{~mL}, \mathrm{pH} \sim 11)$ was added under fast stirring, followed by dropwise addition of tetraethyl orthosilicate (TEOS, $12 \mathrm{~mL}, 8.96 \mathrm{mM}$ in 2-propanol) and then stored for $\sim 12 \mathrm{~h}$ under slow stirring. The particles were then washed and transferred to ethanol as follows: $10 \mathrm{~mL}$ of the as synthesized particles were centrifuged at $2100 \mathrm{~g}$ for 30 min. The supernatant was centrifuged again under the same conditions and precipitates were collected, washed with $5 \mathrm{~mL}$ of water and centrifuged at $1900 \mathrm{~g}$ for $20 \mathrm{~min}$. The supernatant was removed and the particles were added dropwise to $10 \mathrm{~mL}$ of absolute ethanol under sonication $([\mathrm{Au}]=0.247$ $\mathrm{mM})$.

Synthesis of the hybrid $\mathrm{Au}-\mathrm{SiO}_{2}$ CoreSatellites. The assembly experiments were carried out in quartz cells of $1 \mathrm{~cm}$ path length at room temperature. To 2.5 $\mathrm{mL}$ of absolute ethanol were added $32 \mu \mathrm{L}$ of Rhodamine $\mathrm{B}$ isothiocyanate $10^{-5} \mathrm{M}\left([\mathrm{RhB}]_{\text {Final }}=9 \cdot 6 \cdot 10^{-8} \mathrm{M}\right), 172 \mu \mathrm{L}$ of $\mathrm{Au}_{15} @ \mathrm{PVP}\left(0.42 \mathrm{mM}\right.$ in $\mathrm{Au}$, or $2.4 \cdot 10^{12}$ particles $/ \mathrm{mL}$ ) and 490 $\mu \mathrm{L}$ of Janus $\mathrm{Au}_{40}\left(\mathrm{PAA}-\mathrm{MBA} @ \mathrm{SiO}_{2}\right)$ (o.247 mM in $\mathrm{Au}$, or $7 \cdot 5 \cdot 10^{10}$ particles $/ \mathrm{mL}$ ). The amount of $\mathrm{RhB}$ was estimated to be 0.5 molecules $/ \mathrm{nm}^{2}$, taking into account the total available gold surface, considering half of the Janus particles and the $\mathrm{Au}_{15}$ spheres. After each addition the cell was shaken manually. The mixture was incubated for $2 \mathrm{~h}$ in the dark with no apparent aggregation, and then $140 \mu \mathrm{L}$ of $1 \mathrm{mM} \mathrm{HCl}$ was added to initiate the assembly ( $\mathrm{pH}$ changes from $\sim 8.5$ to 5 ) (NOTE: the amount of $\mathrm{HCl}$ may vary when using different stock solutions of $\mathrm{Au}_{40}\left(\mathrm{PAA}-\mathrm{MBA} @ \mathrm{SiO}_{2}\right)$ Janus particles due to slight differences during the washing steps and subsequent transfer to ethanol). After several minutes while monitoring the spectral evolution in the visible, the process was detained by adding $90 \mu \mathrm{L}$ of ammonia. The solution was then transferred to a glass vial and $800 \mu \mathrm{L}$ of Milli Q water and 133 $\mu \mathrm{L}$ of TEOS (o.15 M in EtOH) were added while magnetically stirring the mixture. After $30 \mathrm{~s}$ the solution was stirred slowly for $2 \mathrm{~h}$ to complete the encapsulation. The assembled structures were washed 4 times with $1 \mathrm{~mL}$ of EtOH to remove silica nuclei, recovering them by centrifugation at $2100 \mathrm{~g}$ for $30 \mathrm{~min}$, and finally were dispersed in $1 \mathrm{~mL}$ of $\mathrm{EtOH}$, storing them in the dark to minimize dye photobleaching.

All reactants were purchased from Sigma-Aldrich otherwise indicated.

Cell culture. J774 macrophages were purchased from ATCC (LGC Standards, Barcelona) and were cultured in DMEM media supplemented with $5 \%$ fetal bovine serum (FBS) and $1 \%$ penicillin-streptomycicn (PS). Cells were maintained in humidified atmosphere at $37^{\circ} \mathrm{C}, 5 \% \mathrm{CO}_{2}$ and passaged using pipetting. All reagents were purchased from Invitrogen.

SERS of particles in cells. Cells were detached from growth flasks, counted and plated in a specially made cell slide comprising a normal microscopy glass slide or Suprasil Quartz glass to which a micro-chamber made of PDMS was glued. The surface area of each microchamber was approximately $0.5 \mathrm{~cm}^{2}$, to which 8000 cells were added in a volume of $200 \mu \mathrm{L}$. Once attached, (no functionalization of the glass was needed), medium was replaced with PBS (10 mM, pH 7.4) and the sample was ready for viewing background levels. For SERS imaging of particles within cells, culture medium was removed and 15-30 $\mu \mathrm{L}$ of particles, suspended in PBS, was added to the well and left for $1 \mathrm{~h}$ at $37^{\circ} \mathrm{C}$. After $1 \mathrm{~h}$ the samples were washed using PBS and SERS maps were recorded. For experiments in which SERS signal measurements at 785 $\mathrm{nm}$ were involved, a special Suprasil Quartz glass was used (thereby minimizing background fluorescence).

Raman/SERS spectroscopy. Raman/SERS spectra and corresponding maps were recorded using a Renishaw InVia confocal Raman spectrometer coupled to a Leica DMLM microscope and equipped with three different excitation lasers with wavelengths of $532 \mathrm{~nm}, 633 \mathrm{~nm}$ and $785 \mathrm{~nm}$ as well as two CCD cameras as detectors. SERS spectra of the Janus particles with and without satellites were recorded within $1 \mathrm{~mm}$ quartz UV cells using 1800 (532 and $633 \mathrm{~nm}$ ) or 1200 lines $/ \mathrm{mm}(785 \mathrm{~nm})$ gratings and a long-distance $50 x$ objective with a numerical aperture (NA) of 0.45 . The integration time was set to 1os. The laser powers measured at the focus distance through the objective were $1.1 \mathrm{~mW}$ for $532 \mathrm{~nm}$, $6.0 \mathrm{~mW}$ for $633 \mathrm{~nm}$ and $11.0 \mathrm{~mW}$ for $785 \mathrm{~nm}$. The spectra (except at $532 \mathrm{~nm}$ ) were background corrected and an off-set was applied for better clarity. SERS spectra of encoded Janus particles in J774 macrophage cells were collected with a 40x immersion objective (NA=0.85), in combination with a 600 lines/mm grating by measuring with an integration time of $0.5 \mathrm{~S}$ over the selected $\mathrm{x}-$, $\mathrm{y}$-range at each point of the grid (spacing of $\Delta \mathrm{x}=\Delta \mathrm{y}=2 \mu \mathrm{m}$ ) using a motorized microscope stage. For these measurements, laser powers of $2.0 \mathrm{~mW}(532$ $\mathrm{nm}), 0.5 \mathrm{~mW}(633 \mathrm{~nm})$ and $16.1 \mathrm{~mW}(785 \mathrm{~nm})$ were applied. Two-dimensional SERS maps were created by plotting the baseline corrected intensity of characteristic vibrations at 
each point as a function of grid position. The normalized SERS intensities were displayed on a rainbow-colored code from black (low intensity, $I=0-5)$ through violet $(I=5-15)$, blue $(I=15-30)$, lila-white $(I=30-40)$, green $(I=40-60)$, yellow $(\mathrm{I}=60-65)$, orange $(\mathrm{I}=65-70)$ and red $(\mathrm{I}>70)$.

Instrumentation. Visible-NIR spectra were measured from $1 \mathrm{~cm}$ path length quartz cuvettes in an Agilent 8453 spectrophotometer. Transmission electron microscopy (TEM) analysis was performed with a JEOL JEM $1400 F$ transmission electron microscope operating at an acceleration voltage of $120 \mathrm{kV}$.

\section{RESULTS AND DISCUSSION}

Scheme 1 summarizes the synthetic procedure used for the production of $\mathrm{Au}-\mathrm{SiO}_{2}$ hybrid satellites. Au spheres with an average diameter of $15 \mathrm{~nm}\left(\mathrm{Au}_{15}\right)$, uniformly covered with poly(vinylpyrrolidone) $(\mathrm{Mw}=10 \mathrm{~kg} / \mathrm{mol}, \mathrm{PVP})$, and $\mathrm{Au}-\mathrm{SiO}_{2}$ Janus particles comprising a $40 \mathrm{~nm} \mathrm{Au}$ core and a silica semishell, both dispersed in ethanol, were employed as building blocks (see Experimental Section for synthetic details). The Janus nanoparticles were prepared following a previously reported procedure, using both 4mercaptobenzoic acid (4-MBA) and polyacrylic acid (PAA) as ligands, to grow a silica semishell over the 4-MBA covered part of the Au surface (Figure $2 \mathrm{~A}$ ).$^{50,51}$ Both types of particles were first incubated with Rhodamine $B$ isothiocyanate $(\mathrm{RhB}$, 9.6 $\left.\cdot 10^{-8} \mathrm{M}\right)$ in ethanol. This Raman reporter was selected because it features a high Raman cross section, as well as an isothiocyanate group that facilitates adsorption to gold particles, even when covered by a polymer shell, and high stability in both acidic and basic media within the $\mathrm{pH}$ range between 5 and 11. We thus expect that RhB adsorbs on both the small $\mathrm{Au}_{15}$ spheres and the exposed $\mathrm{Au}$ surface of the Janus particles ( 1 molecule per $2 \mathrm{~nm}^{2}$ of total Au surface available)..$^{52}$

Scheme 1. Rhodamine B isothiocyanate ( $R h B)$ is incubated with $\mathrm{Au}_{15} @ \mathrm{PVP}$ spheres and Janus $\mathrm{Au}_{40}\left(\mathrm{PAA}-\mathrm{MBA} @ \mathrm{SiO}_{2}\right)$ particles. Self-assembly occurs when the $\mathrm{pH}$ is set to 5 and can be detained by increasing solution $\mathrm{pH}$. A silica shell is finally grown to stabilize the hybrid nanostructures.

Therefore, two Raman active species are incorporated within the final nanostructures: RhB in the hot spots generated at the gaps between assembled Au particles, and 4-MBA at the Au-silica interface of the Janus nanoparticles. Importantly, addition of the dye did not trigger aggregation of the particles, as indicated by UV-vis spectroscopy (Figure 1). Aggregation did not occur because of the basic $\mathrm{pH}$ of the mixture ( $\mathrm{pH}$-8.5), at which PAA is deprotonated, thereby providing electrostatic stability. However when the $\mathrm{pH}$ was decreased to 5 via addition of $1 \mathrm{mM} \mathrm{HCl}_{\mathrm{aq}}$, aggregation started through van der Waals forces and electrostatic attraction between PVP and PAA due to the protonation of PAA ( $\mathrm{pKa}$ 4.8). ${ }^{53}$ The assembly is indicated by redshift and broadening of the plasmon band, due to plasmon coupling (see Figure
1). ${ }^{46,54}$ Although a sufficient amount of $\mathrm{Au}_{15}$ spheres were added to cover $\sim 80 \%$ of the available Au surface at the Janus particles, the assembly process was stopped after 5 minutes (by adding ammonia, increasing the $\mathrm{pH}$ of the mixture to $\sim 11$ ) to avoid the formation of bigger clusters comprising three or more Janus particles. It is interesting to note that no clusters comprising $\mathrm{Au}_{15} @$ PVP only were observed in TEM images, but instead they are always found to adsorb on Janus particles, either forming hybrid satellites or acting as bridges to produce dimers or bigger clusters. The low particle concentration in the TEM image in Figure $2 \mathrm{~B}$ is due to the process used to avoid excessive particle aggregation during drying on the carbon-coated grid. As the assembly is a fast and dynamic process, five drops $(8.5 \mu \mathrm{L}$ each) were casted on the grid, which was placed over paper. The paper support absorbed the excess of solution thereby providing more separated particles as well as a more realistic idea of what was present in solution.

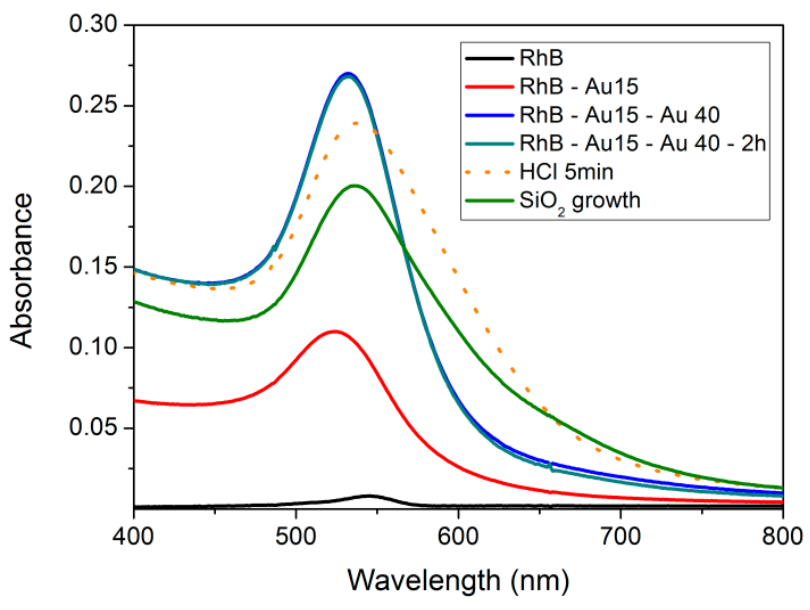

Figure 1. Spectral evolution during assembly and silica encapsulation.

Since the assembled nanoparticles are dispersed at high $\mathrm{pH}$, silica shells can be grown using the well-known Stöber method, ${ }^{55}$ so as to fix and protect the obtained structures (Figure $2 \mathrm{C}, \mathrm{D})$. Growing the silica shell immediately after completing the assembly helps preventing the dissolution of the silica semishell from the Janus nanoparticles. The final outer shell is stable in ethanol for extended periods of time and at least for one month in water, with no apparent dissolution as seen by TEM. Figure $2 \mathrm{C}, \mathrm{D}$ shows representative TEM images of the final hybrid satellites after washing to remove excess organic molecules. Various types of particles can be clearly seen, including satellites made of one Janus particle and a few small spheres, dimers comprising two Janus particles linked by small $\mathrm{Au}_{15}$ spheres and some silica nucleation. The latter and the non-assembled $\mathrm{Au}_{15}$ spheres can be easily removed by 4 -fold centrifugation and washing with ethanol. Analysis of $\sim 500$ particles revealed that ca. $49 \%$ hybrid satellites comprise one $\mathrm{Au}_{40}$ core with at least one $\mathrm{Au}_{15}$ particle, whereas $23 \%$ are $\mathrm{Au}_{40}$ dimers, $24 \%$ nonassembled $\mathrm{Au}_{40}$ particles, and some $4 \%$ are larger clusters, all of them covered with silica. This variation in the nanoarchitecture of the particles may lead to some differences in the plasmonic response and enhancing efficiency but is of little relevance to imaging as shown below. 


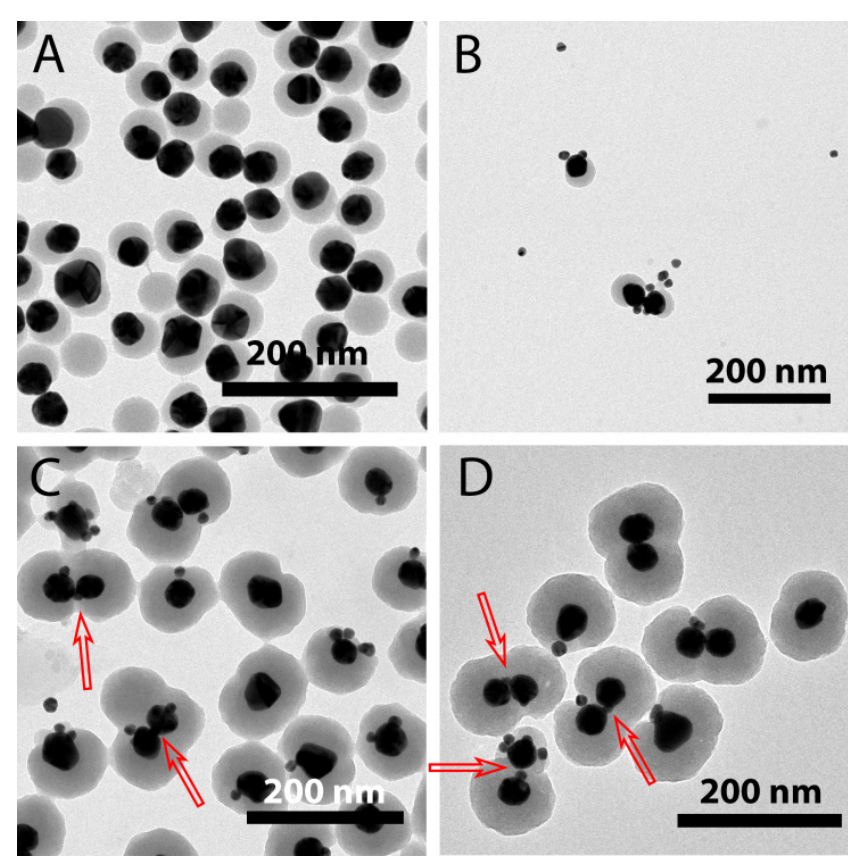

Figure 2. Representative TEM images of: A) $\mathrm{Au}_{40}(\mathrm{PAA}-$ $\mathrm{MBA} @ \mathrm{SiO}_{2}$ ) Janus particles; B) Intermediate structures formed after 5 min of assembly; C-D) $\mathrm{Au}-\mathrm{SiO}_{2}$ hybrid satellites. Red arrows indicate the position of $\mathrm{Au}_{15}$ acting as linkers for the Janus particles.

SERS measurements were carried out in water (upon transfer from ethanol) so as to minimize interference from the solvent and because it is a more suitable solvent toward experiments with cells. The concentrations of particles were estimated as $6.1 \cdot 10^{-11} \mathrm{M}$ of Janus and $7.1 \cdot 10^{-9} \mathrm{M}$ of $\mathrm{Au}_{15}$, considering that no loses occurred during assembly, subsequent silica growth, and washing. In reality, non-adsorbed $\mathrm{Au}_{15}$ particles were removed during washing due to their smaller weight as compared to the hybrid satellites. 4-MBA was added during the synthesis of $\mathrm{Au}-\mathrm{SiO}_{2}$ Janus particles, at a concentration of $2 \cdot 7 \cdot 10^{-5} \mathrm{M}$ (35 molecules $/ \mathrm{nm}^{2}$ ), while $\mathrm{RhB}$ was incorporated during the assembly process, at a concentration of $9.6 \cdot 10^{-8} \mathrm{M}$ (o.5 molecules $\left./ \mathrm{nm}^{2}\right)$.

The SERS spectra of the hybrid satellites in water upon excitation with three different wavelengths (532, 633 and 785 $\mathrm{nm}$ ) are shown in Figure 3. Upon $532 \mathrm{~nm}$ excitation (green spectrum), only scattered frequencies were detected that are related to the excitation of characteristic $\mathrm{RhB}$ vibrations $\left(1620,1580,1560,1340,1280\right.$ and $\left.1210 \mathrm{~cm}^{-1}\right)$. The peak positions are in good agreement with the modes reported for RhB adsorbed on micron sized $\mathrm{Ag}$ powder or on $\mathrm{Ag}$ nanoshells upon excitation with 514 and $633 \mathrm{~nm}^{56,57}$ In contrast, totally different frequencies were scattered upon $785 \mathrm{~nm}$ excitation. The signals correspond to the excited vibrational states of the second Raman label, 4-MBA $\left(1585,1075,1180\right.$ and $700 \mathrm{~cm}^{-1}$, black curve), which do not overlap with the vibrations of RhB. Using the $633 \mathrm{~nm}$ excitation wavelength, a more complex spectrum was recorded in which the scattered 4-MBA frequencies dominate (black dots over the red curve in Figure 3) and less intense contributions from scattered RhB frequencies (marked by green dots). A control experiment using Janus particles and small $\mathrm{Au}_{15 \mathrm{~nm}}$ spheres without aggregation was carried out to study the relation between the hybrid structure and the observed color-selective SERS behavior of the incorporated Raman tags. Strong SERS signals were recorded with $633 \mathrm{~nm}$ excitation whereas a much lower signal was detected in the $785 \mathrm{~nm}$ channel. As the signal originates from 4-MBA within the Janus building blocks, the intensities using the $785 \mathrm{~nm}$ channel are comparable in both systems (black spectrum in Figures 3 and $\mathrm{S}_{1}$ ). In the $532 \mathrm{~nm}$ channel only background fluorescence was detected, arising from unbound RhB molecules (see Figure $\mathrm{S}_{1}$ ). This clearly indicates that the assembly of satellites is required for $\mathrm{RhB}$ detection and that the SERS signal originates exclusively from molecules located within the hot spots between the central Janus particles and the small satellites. The strong SERS signal can be explained by the enhanced Raman cross section at $532 \mathrm{~nm}$ due to the RhB electronic resonance state around $550 \mathrm{~nm} . .^{56}$ These results demonstrate the ability of this system to act as a SERS switcher in water, allowing us to turn on or off the dye molecules at will by using different laser excitation colors. This offers the possibility for multiplex particle tracking via SERS using the excitation wavelength as an additional channel.

The experimental SERS enhancement factor (EF) of the hybrid satellite assemblies were calculated using the intensity ratio between SERS and Raman scattering (RS) signals, normalized by the number of contributing molecules $(\mathrm{N})$, according to $\mathrm{EF}=(\mathrm{I} / \mathrm{N})_{\mathrm{SERS}}:(\mathrm{I} / \mathrm{N})_{\mathrm{RS}} \cdot{ }^{58}$ Due to the low RS signals, the measurements were carried out from a solid powder and compared to a thin film assembly drop casted onto glass, leading to wavelength dependent EFs of $4.2 \times 10^{6}, 2.6 \times 10^{6}$ and $4.9 \times 10^{6}$ for 785,633 and $532 \mathrm{~nm}$ respectively (more details in the SI). ${ }^{59,60}$

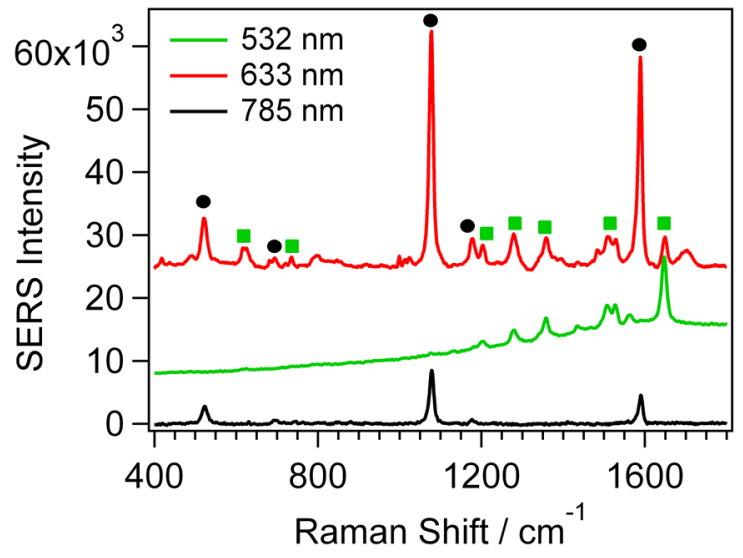

Figure 3. SERS spectra of hybrid satellites in water using 3 different laser wavelength lines: $532 \mathrm{~nm}$ (green line), $785 \mathrm{~nm}$ (black line) and $633 \mathrm{~nm}$, (red line). The green dots indicate $\mathrm{RhB}$ vibrations and black dots the 4 -MBA signature.

We next show that the molecular fingerprints of both RhB and 4-MBA can also be detected when the hybrid particles are internalized by cells in vitro. We selected the continuous macrophage cell line J774 because it is quickly adherent and actively phagocytoses (uptakes) particles. Both factors were important because of the small working volume of the sample and therefore long term incubation times of the cells with the particles were not possible, due to risk of complete evaporation of the media solution. Therefore, cells do not have an elongated form but are instead round (Figure $4 \mathrm{~A}$ ). Hybrid satellites were added to cells and SERS spectra at excitation 
wavelengths of 532, 633 and $785 \mathrm{~nm}$ were collected after $1 \mathrm{~h}$ incubation from a single cell (Figure $4 \mathrm{~B}-\mathrm{D}$ ). As the cell did not move noticeably over the measurement period, the same cell could be imaged with all excitation wavelengths. For each wavelength one individual SERS spectrum (green curve for $532 \mathrm{~nm}$ in B, black curve for $785 \mathrm{~nm}$ in $C$, and red curve for $633 \mathrm{~nm}$ in D) recorded at a single point within the cell was chosen and compared with the corresponding colordependent reference from the hybrid satellites measured in solution without cells (grey lines in Figure ${ }_{4} \mathrm{~B}-\mathrm{D}$ ). The SERS spectra obtained in cells perfectly reflect the fingerprints of the RhB label at $532 \mathrm{~nm}$, of the 4-MBA label at $785 \mathrm{~nm}$ and of both labels at $633 \mathrm{~nm}$. No additional peaks were observed from the cell or the buffer solution under the present experimental conditions. As the reference spectra of hybrid satellites in solution were measured using 1800 or 1200 lines $/ \mathrm{mm}$ gratings, whereas the cell maps were recorded with a 600 lines/mm grating (all wavelengths), a slight broadening of the SERS features in the cell compared to the reference sample was observed. The reference spectra were collected with

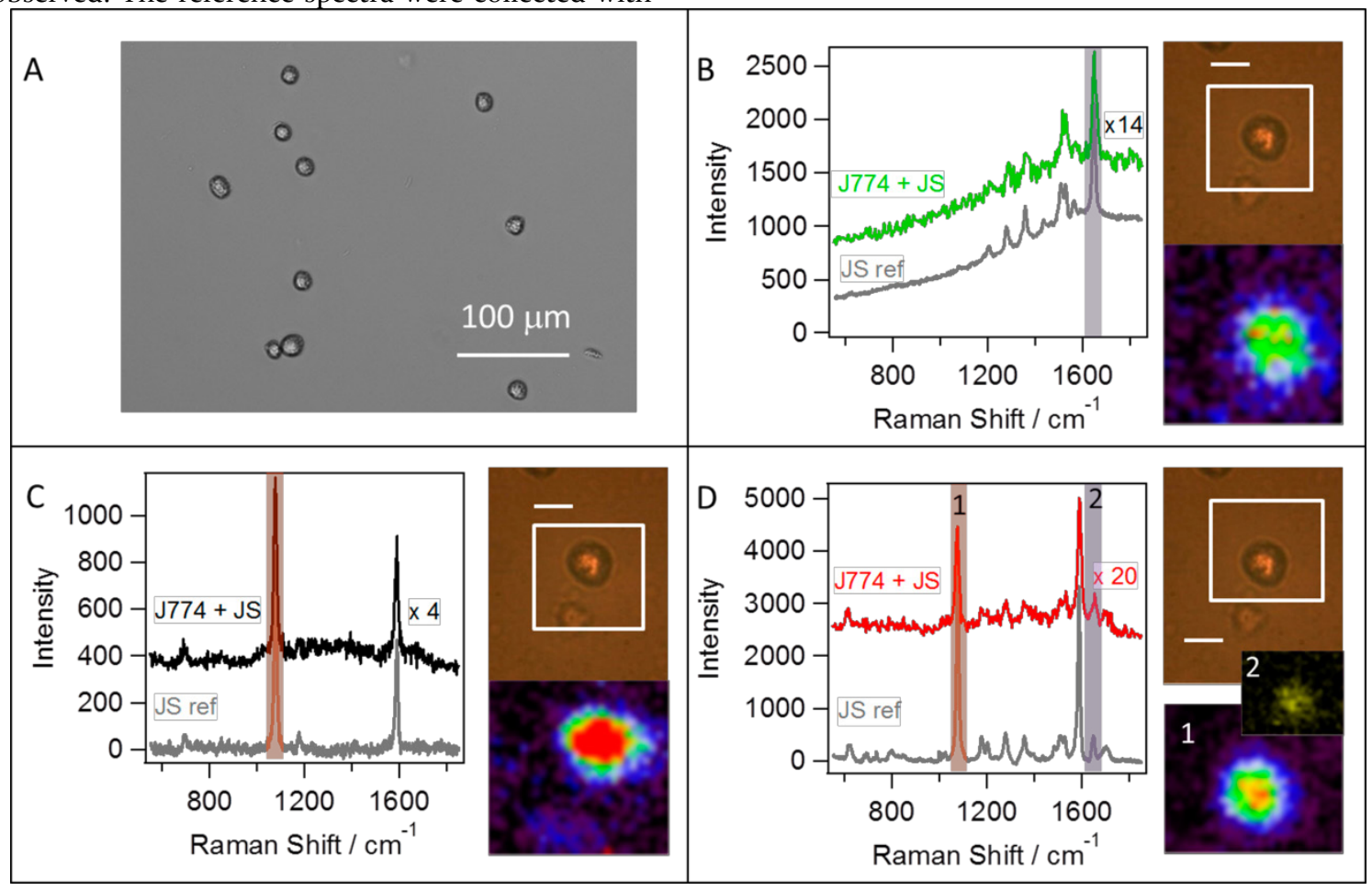

Figure 4. A: Representative transmitted light image of the macrophage cell line J744 before incubation with hybrid satellites; BD: color-dependent SERS spectra of J744 (left), white-light image and SERS maps (right) recorded 1 h after incubation with hybrid satellites from the same single cell, at $532 \mathrm{~nm}$ (B), $785 \mathrm{~nm}$ (C) and $633 \mathrm{~nm}$ (D). To facilitate comparison of the cell spectra (J774+JS, green, black and red curves) with the corresponding reference spectra from hybrid satellites in water at the same wavelengths (JS ref, grey curves), the SERS intensities were multiplied by: 14 (B), 4 (C) and 20 (D). SERS maps for each excitation color were created by plotting the intensity of the selected mode (marked in the SERS spectrum with an orange bar for 4-MBA at $1078 \mathrm{~cm}^{-1}$ and a purple bar for $\mathrm{RhB}$ at $1617 \mathrm{~cm}^{-1}$ ) within the selected area (marked by the white frame in the white-light image) using a color code from black (low intensity) to red (highest intensity); the color code in the SERS map $2\left(\mathrm{RhB} / 1617 \mathrm{~cm}^{-1}\right)$ in $\mathrm{D}$ ranged from black (low) to bright yellow (high intensity). The white scale bar corresponds to $20 \mu \mathrm{m}$.

and applied for multiplex labeling applications, both in aqueous solutions and in color-sensitive SERS bioimaging. This concept should be interesting for applications where the independent detection of two different components using the same analytical technique is of advantage. Such a scenario is potentially interesting, e.g. in drug delivery schemes. Through replacement of RhB by a drug molecule and intro-
We have shown that hybrid satellites composed of silica and gold nanoparticles can be encoded with two different dyes long integration times of $10 \mathrm{~s}$ instead of $0.5 \mathrm{~s}$, applied for the cell. Indeed, the signal-to-noise ratio of hybrid satellites in the less intense vibrations.

The intensity distribution of the characteristic vibrations appear to show that the hybrid satellites filled the interior of the macrophage (Figure $4 \mathrm{~B}-\mathrm{D}$ ). By conducting SERS mapping mode using short step sizes $(\leq 1 \mu \mathrm{m})$, a higher level of lateral
moder resolution for the hybrid satellites could be obtained (Figure S2). Importantly, although the cells were not fully adhered short $(1 \mathrm{~h})$, endocytosis of particles was noted at high levels and was not affected by washing. It is possible that part of membrane, however bearing in mind the phagocytic nature of J774's, such levels should be negligible. 
duction of a disassembly step of the hybrid satellites, drug tracking and release could be directly controlled via SERS signal intensity using the green laser excitation. Additionally, tracking and fate of the delivery medium, i.e. the Au nanoparticles, can be independently monitored by the SERS fingerprint of the fixed residue molecule just by switching to another excitation line. These assemblies are thus a proof of concept showing the capabilities of these structures, but the design can be varied to extend their possible applications. For example, the outer silica layer could be modified to make these structures specifically bind to cancer cells.

\section{ASSOCIATED CONTENT}

SERS control experiment and SERS mapping of cells. This material is available free of charge via the Internet at http://pubs.acs.org.

\section{AUTHOR INFORMATION}

\section{Corresponding Author}

*Email: llizmarzan@cicbiomagune.es

\section{ACKNOWLEDGMENT}

Funding from the European Research Council (ERC Advanced Grant \#267867 Plasmaquo) and the Spanish MINECO (Grant MAT2013-46101-R) is gratefully acknowledged. D.R.-F. acknowledges receipt of an F.P.U. scholarship from the Spanish Ministry of Education and Culture. Authors thank A. Ruiz de Angulo Dorronsoro for guidance on cell experiments preparation.

\section{REFERENCES}

1. Fleischmann, M.; Hendra, P. J.; McQuillan, A. J. Chem. Phys. Lett. 1974, 26, 163.

2. Albrecht, M. G.; Creighton, J. A. J. Am. Chem. Soc. 1977, 99, 5215 .

3. Jeanmaire, D. L.; van Duyne, R. P. J. Electroanal. Chem. 1977, 84, 1.

4. Pettinger, B.; Wenning, U. Chem. Phys. Lett. 1978, 56, 253.

5. Creighton, J. A.; Blatchford, C. G.; Albrecht, M. G. J. Chem. Soc. Faraday Trans. II 1979, 75, 806.

6. Arvind, P. K.; Nitzan, A.; Metiu, H. Surf. Sci. 1981, $110,189$.

7. Xu, H.; Aizupurua, J.; Käll, M.; Apell, P. Phys. Rev. E 2ooo, 62, 4318.

8. Sonntag, M. D.; Klingsporn, J. M.; Zrimsek, A. B.; Sharma, B.; Ruvuna, L. K.; Van Duyne, R. P. Chem. Soc. Rev. 2014, 43, 1230.

9. Jiang, J.; Bosnick, K.; Maillard, M.; Brus, L. J. Phys. Chem. B 2003, 107, 9964.

10. Le Ru, E. C.; Etchegoin, P. G.; Meyer, M. J. Chem. Phys. 2006, 125, 204701.

11. Futamata, M.; Maruyama, Y.; Ishikawa, M. J. Mol. Struct. 2005, 735, 75.

12. Futamata, M. Faraday Discuss. 2006, 132, 45.

13. Sasic, S.; Itoh, T.; Ozaki, Y. J. Raman Spectrosc. 2005, 36, 593.

14. Fang, Y.; Seong, N.H.; Dlott, D.D. Science 20o8, 321, 388.

15. Stranahan, S. M.; Willets, K. A. Nano Lett. 2010, 10, 3777.

16. Isola, N. R.; Stokes, D. L.; Vo-Dinh, T. Anal. Chem. 1998, 70, 1352.

17. Graham, D.; Mallinder, B. J.; Whitcombe, D.; Watson, N. D.; Smith, W. E. Anal. Chem. 2002, 74, 1069.

18. Cao, Y.-W. C.; Jin, R. C.; Mirkin, C. A. Science 2002, 297, 1536.
19. Ni, J.; Lipert, R. J.; Dawson, G. B.; Porter, M. D. Anal. Chem. 1999, 71, 4903.

20. Cao, Y.-W. C.; Jin, R. C.; Mirkin, C. A. J. Am. Chem. Soc. 2003, 125, 14676.

21. Grubisha, D. S.; Lipert, R. J.; Park, H. Y.; Driskell, J.; Porter, M. D. Anal. Chem. 2003, 75, 5936.

22. Kneipp, J.; Kneipp, H.; Rajadurai, A.; Redmond, R. W.; Kneipp, K. J. Raman Spectrosc. 2009, 40, 1.

23. Kennedy, D. C.; Hoop, K. A.; Tay, L.-L.; Pezacki, J. P. Nanoscale 2010, 2, 1413.

24. Pallaoro, A.; Braun, G. B.; Reich, N. O.; Moskovits, M. Small 2010, 6, 618.

25. Wang, Y.; Seebald, J. L.; Szeto, D. P.; Irudayaraj, J. ACS Nano 2010, 4, 4039.

26. Mulvaney, S. P.; Musick, M. D.; Keating, C. D.; Natan, M. J. Langmuir 2003, 19, 4784.

27. Doering, W. E.; Nie, S. Anal. Chem. 2003, 75, 6171.

28. McCabe, A. F.; Eliasson, C.; Prasath, R. A.; HernandezSantana, A.; Stevenson, L.; Apple, I.; Cormack, P. A. G.; Graham, D.; Smith, W. E.; Corish, P.; Lipscomb, S. J.; Holland, E. R.; Prince, P. D. Faraday Discuss. 2006, 132, 303.

29. Faulds, K.; McKenzie, F.; Smith, W. E.; Graham, D. Angew. Chem. Int. Ed. 2007, 46, 1829.

30. Su, X.; Zhang, J.; Sun, L.; Koo, T.-W.; Chan, S.; Sundararajan, N.; Yamakawa, M.; Berlin, A. A. Nano Lett. 2005, 5, 49 .

31. Brown, L.; Doorn, S. K. Langmuir 2008, 24, 2277.

32. Braun, G. B.; Pavel, I.; Morill, A. R.; Seferos, D. S.; Bazan, G. C.; Reich, N. O.; Moskovits, M. J. Am. Chem. Soc. 2007, 129, 7760 .

33. Fabris, L.; Dante, M.; Nguyen, T.-Q.; Tok, J. B.-H.; Bazan, G. C. Adv. Funct. Mater. 2008, 18, 18.

34. Braun, G. B.; Lee, S.J.; Laurence, T.; Fera, N.; Fabris, L.; Bazan, G. C.; Moskovits, M.; Reich, N. O. J. Phys. Chem. C 2009, 113, 13622.

35. Xia, X.; Li, W.; Zhang, Y.; Xia, Y. Interface Focus 2013, 3, 20120092

36. Qian, X.; Peng, X.-H.; Ansari, D. O.; Yin-Goen, Q.; Chen, G. Z.; Shin, D. M.; Yang, L.; Young, A. N.; Wang, M. D.; Nie, S. Nature Biotechnology 2008, 26, 83.

37. Zavaleta, C. L.; Smith, B. R.; Walton, I.; Doering, W.; Davis, G.; Shojaei, B.; Natan, M. J.; Gambhir, S. S. Procs. Nat. Acad. Sci. 2009, 106, 13511.

38. Gellner, M.; Kömpe, K.; Schlücker, S. Anal. Bioanal. Chem. 2009, 394, 1839.

39. Maiti, K. K.; Dinish, U. S.; Samanta, A.; Vendrell, M.; Soh, K.-S.; Park, S.-J.; Olivo, M.; Chang, Y.-T. Nano Today 2012, 7, 85.

40. von Maltzahn, G.; Centrone, A.; Park, J.-H.; Ramanathan, R.; Sailor, M. J.; Hatton, T. A.; Bhatia, S. N. Adv. Mater. 2009, 21, 3175.

41. Xiao, M.; Nyagilo, J.; Arora, V.; Kulkarni, P.; Xu, D.; Sun, X.; Dave, D. P. Nanotechnology 2010, 21, 035101.

42. Kircher, M. F.; de la Zerda, A.; Jokerst, J. V.; Zavaleta, C. L.; Kempen, P. J.; Mittra, E.; Pitter, K.; Huang, R.; Campos, C.; Habte, F.; Sinclair, R.; Brennan, C. W.; Mellinghoff, I. K.; Holland, E. C.; Gambhir, S. S. Nature Med. 2013, 18, 829.

43. Nima, Z. A.; Mahmood, M.; Xu, Y.; Mustafa, T.; Watanabe, F.; Nedosekin, D. A.; Juratli, M. A.; Fahmi, T.; Galanzha, E. I.; Nolan, J. P.; Basnakian, G.; Zharov, V. P.; Biris, A. S. Sci. Rep. 2014, 4, 4752.

44. Wustholz, K. L.; Henry, A.-I.; McMahon, J. M.; Freeman, R. G.; Valley, N.; Piotti, M. E.; Natan, M. J.; Schatz, G. C.; Van Duyne, R. P. J. Am. Chem. Soc 2010, 132, 10903.

45. Kleinman, S. L.; Sharma, B.; Blaber, M. G.; Henry, A.-I.; Valley, N.; Freeman, R. G.; Natan, M. J.; Schatz, G. C.; Van Duyne, R. P. J. Am. Chem. Soc. 2013, 135, 301. 
46. Cha, H.; Yoon, J. H.; Yoon, S. ACS Nano 2014, 8, 8554.

47. Rodríguez-Fernández, D.; Liz-Marzán, L. M. Part. Part. Syst. Charact. 2013, 30, 46.

48. Turkevich, J.; Stevenson, P. C.; Hillier, J. Discuss. Faraday Soc. 1951, 11, 55 .

49. Graf, C.; Vossen, D. L. J.; Imhof, A.; van Blaaderen, A. Langmuir 2003, 19, 6693.

5o. Rodríguez-Fernández, D.; Altantzis, T.; Heidari, H.; Bals, S.; Liz-Marzán, L. M. Chem. Commun. 2014, 50, 79.

51. Chen, T.; Chen, G.; Xing, S.; Wu, T.; Chen, H. Chem. Mater. 2010, 22, 3826 .

52. Qian, X.; Emory, S. R.; Nie, S. J. Am. Chem. Soc. 2012, 134, 2000.

53. Michaels, A. S.; Morelos, O. Ind. Eng. Chem. 1955, 47, 1801

54. Liz-Marzán, L. M. Langmuir 2006, 22, 32.

55. Stöber, W.; Fink, A.; Bohn, E. J. Colloid Interface Sci. 1968, 26,62 .
56. Kim, K.; Lee, Y. M.; Lee, J. W.; Shin, K. S. Langmuir 2009, 25, 2641.

57. Kim, K.; Lee, H. B.; Lee, Y. M.; Shin, K. S. Biosens. Bioelectr. 2009, 24, 1864.

58. Cai, W. B.; Ren, B.; Li, X. Q.; She, C. X.; Liu, F. M.; Cai, X. W.; Tian, Z. Q. Surf. Sci. 1998, 406, 9.

59. Khan, M. A.; Hogan, T. P.; Shanker, B. J. Raman Spectros. 2008, 39, 893 .

6o. Jiang, X.; Zhang, L.; Wang, T.; Wan, Q. J. Appl. Phys. 2009, 106, 104316. 
Table of Contents Graphics

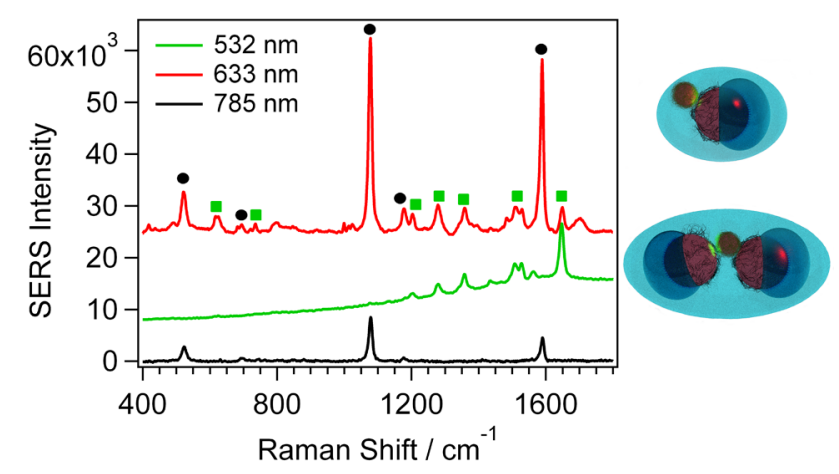

